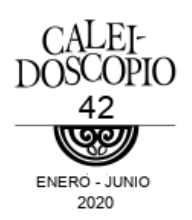

\title{
L'année dernière a Marienbad, de Alain Resnais
}

\author{
L'année dernière a Marienbad, by Alain
}

Resnais

RAQUEL MERCADO SALAS

Universidad Autónoma de Aguascalientes, México

\section{RESUMEN}

El presente ensayo se enmarca en el ámbito de Filosofía y Cine, en el que se desarrolla la lectura de una estética de la diferencia y repetición, para localizar la ilusión de continuidad en la película de Alain Resnais. El eterno retorno, encontrado en el mecanismo cinematográfico es orquestado en la composición de Resnais a través de este filme y ofrece tanto una gama de sensaciones (vacío, horror, vértigo), como también relaciones con los problemas del cine dentro del cine: su relación con las artes, el problema de la espacialidad, la condición ontológica de la fotografía y el problema del tiempo en la imagen movimiento.

Palabras clave: repetición; fotografía; eterno retorno; ilusión cinematográfica; temporalidad.

\section{ABSTRACT}

This essay is framed in the field of Philosophy and Cinema, in which the reading of an aesthetic of difference and repetition 
is developed to locate the illusion of continuity in the Alain Resnais film. The eternal recurrence found in the cinematographic mechanism is orchestrated in the composition by Resnais through this film and offers a range of sensations (emptiness, horror, vertigo); also shows his relations with the problems of cinema within the cinema: its relationship with arts, the problem of spatiality, the ontological condition of photography and the problem of time in the movement image.

Keywords: repetition; photography; eternal recurrence; film illusion; temporality.

I have been here before, But when or how I cannot tell: I know the grass beyond the door, The sweet keen smell, The sighing sound, the lights around the shor. Dante Gabriel Rossetti

«Hoy, en esta isla, ha ocurrido un milagro: el verano se adelantó»' escribe Bioy Casares en La invención de Morel, «lo impactante es que se puede filmar el milagro. Eso es lo notable»², escribe Alain Badiou en Pensar el cine 1. Entre una y otra expresión insertamos un objeto mental y sensible, L 'année dernière à Marienbad de Alain Resnais, largometraje objeto del presente análisis. En primer lugar, hacer una

\footnotetext{
${ }^{1}$ Bioy Casares, Adolfo La invención de Morel. Ed. Cátedra, p. 89.

${ }^{2}$ Badiou, Alain, Pensar el cine 1, P. 41.
} 
sinopsis implica, una comprensión de la trama. En el caso de L'année dernière a Marienbad no es sencillo por el uso del falso raccord que pone en entredicho al relato cinematográfico, nos dice el mismo Resnais: «cada espectador tiene su propia explicación de la película, es una manera de mostrarle mi estima» ${ }^{4}$. Sin embargo, sabemos, para comenzar, algo del filme a) está influenciado por la Invención de Morel de Adolfo Bioy Casares y b) se le presenta como un diálogo entre un hombre y una mujer; él trata de convencerla de que se conocieron hace un año en Marienbad y le pide además darse a la fuga en su compañía. La mujer ha olvidado ese encuentro, o quizás el encuentro es siempre en el presente del diálogo, pero, esto no es evidente en la factura del filme.

Hay algo que se resiste a ser contado en L'année dernière a Marienbad, una especie de olvido a causa de una fractura en el tiempo, cuando estamos a punto de comprender el curso del relato parece regresarnos al principio a fuerza de caminar por un anillo de Möebius. Esta cercanía y lejanía de la comprensión de lo que está pasando en el filme bien podríamos relacionarla con lo que Deleuze plantea como el primero de los problemas percibidos en la relación entre la Filosofía y el Cine: «Bergson tiene explícitamente en cuenta al cine pero para denunciar una ilusión que, según él, el cine no inventa pero promueve, ilusión a la cual el cine da una extensión hasta allí desconocida. El título del capítulo-El mecanismo cinematográfico y la ilusión mecanicista-trata, o al menos

\footnotetext{
${ }^{3}$ L'année dernière a Marienbran (Francia, Italia, Alemania, Austria, 1961), una película bajo la dirección de Alain Resnais, producción de Pierre Courau y Raymond Froment, Guion de Alain Robbe-Grillet, música de Francis Seyrig, Fotografía de Sasha Vierny, vestuario de Coco Chanel y Bernard Evein. Productora Cineriz y distribución de StudioCanal. Protagonistas: Delphine Seyrig, Giorgio Albertazzi, Sacha Pitoeff. Estaremos citando esta versión de la red: https://www.youtube.com/watch? v=NZeYRTCgRju, verificada el 18 de agosto, 2018.

4 Entrevista a Alain Resnais en 1961 https://www.youtube.com/watch?v=gTg knL4cks verificada el 18 de agosto, 2018.
} 
parece o creemos que trata de denunciar una ilusión» ${ }^{5}$. La ilusión a la que nos introduce Resnais es la de la experiencia de la repetición, de un encuentro ya vivido, que es, y además será en el futuro, una y otra vez.

En la novela de Bioy un prófugo de la justicia decide embar-carse hacia un lugar en el que quizás encuentre la muerte, pero prefiere ese riesgo a ser aprehendido; en la isla, lugar al que llega, su búsqueda por la supervivencia le hace entrar a escondidas en una especie de hotel de lujo en el que busca provisiones, quiere encender a los motores que brindan energía a los espacios vacíos, oscuros y con el cansancio después del esfuerzo escucha voces de una serie de personajes que observa sin ser visto y de los cuales comienza a saber características de su intimidad. Entre esos personajes está Faustine, una mujer a la que observa realizar una y otra vez en una eterna repetición la misma escena: ver el atardecer, con un foulard y un libro de compañía. Así, este personaje fugitivo comenzará a intrigarse cada vez más con esa presencia femenina hasta el grado de enamorarse y buscar el contacto. Para su humillación los habitantes del castillo lo ignoran, tanto en sus desplantes como en los tributos que realiza-por ejemplo, un pequeño jardín ofrecido a Faustine. La desesperación y la paranoia están por apoderarse de él pues comienza a pensar que es invisible o ignorado, hasta que se da cuenta que todos aquellos habitantes y sus movimientos automáticos y cotidianos no son sino la repetición de un aparato inventado por Morel y que tienen como destino decir una y otra vez los mismos diálogos, hacer los mismos gestos corporales, aparecer y desaparecer a la misma hora de cada día en aquella isla desierta.

${ }^{5}$ Deleuze, Gilles. Bergson y las Imágenes. Ed. Cactus. P. 19. 
...de un momento a otro, en esta pesada noche de verano, los pajonales de la colina se han cubierto de gente que baila, que pasea y que se baña en la pileta, como veraneantes instalados desde hace tiempo en los Teques o en Marienbad'.

El repeluzno frente a una eterna repetición en la que la única diferencia está dada por el espectador fugitivo en la más completa soledad es el quid de la breve novela de Casares. Esa potencia maquinal de la reproducción parecía estar hecha para el cine, y al mismo tiempo no. He ahí el milagro. El milagro es que el verano se adelantó, como se adelanta la reproducción de un atardecer en un filme. El milagro es hacer presente a la discontinuidad, bajo el manto de la «continuidad» cinematográfica, como diría Badiou. Para que esa ilusión se haga presente debe haber algo que lo permita, y ese algo lo debe saber el prestidigitador de la ilusión, o estar implícita en la ilusión misma. Por ello debemos preguntarle a la obra como primer paso. Al observar el filme podemos plantear cuatro elementos en yuxtaposición que se establecen en él: a) la arquitectura, b) el teatro, la pintura y la fotografía, c) el olvido y la memoria y d) el juego. Todos estos elementos implican la experiencia en la que el espectador intenta orientarse y que fugitiva, al igual que el protagonista de la Invención de Morel, se encuentra en constante movimiento.

El primer elemento que aparece al inicio del filme es el de la arquitectura y con ella el problema del espacio en el relato cinematográfico. Hay susurros que poco a poco se van distinguiendo en la enumeración de objetos por parte de una voz masculina que emerge de la oscuridad y da la sensación de un punto de vista subjetivo pues es la cámara la que intenta orientarse en el espacio insinuado por la voz y por el tenebrismo en el uso de la luz. Esta acción inicial, implica lo que Gaudreault y Jost plantean como estrategia para poner

${ }^{6}$ Bioy Casares, Adolfo Op. Cit. P. 91. 
entre paréntesis la irrenunciable condición espacial del relato cinematográfico «La acción puede producirse en una oscuridad relativa y así privar momentáneamente al espectador de un buen número de coordenadas espaciales»»? esta inicial, oscuridad relativa, está marcada por seis planos secuencia que muestran desde distintos ángulos el espacio en el que experimentará el relato el espectador. La voz enuncia de qué está compuesto el espacio: de columnas, de estatuas, de corredores, de salones vacíos, de galerías, de formas barrocas; los ángulos de las tomas son en contrapicado, en primer plano de muros y lámparas, todo ello propuesto en una iluminación que simula una lámpara que recorre el interior de lo que parece un hotel barroco, profuso, de otro tiempo. En el plano secuencia número seis aparece un hombre caminando por un largo pasillo a nuestro encuentro, esa primera aparición está enmarcada en una longitud visual que desde la perspectiva usada muestra un marco de una puerta, donde se observa el marco de otra puerta más pequeña, y así en la multiplicación ad infinitum, obsequiándonos la sensación de horror vacui tan característica del barroco. Todas las formas de los objetos, los candelabros, los pasillos, las columnas, los espejos nos introducen en el laberinto voluptuoso de la repetición del mismo filme.

El séptimo plano nos introduce al segundo elemento de yuxtaposiciones y que está relacionado con las artes plásticas y escénicas: aparece ante la cámara, que se ha colocado de izquierda a derecha, la pintura de un jardín-escenario de un encuentro entre un hombre y una mujer en otro momento del filme y de escenografía en una obra de teatro en donde de nuevo un hombre y una mujer representan el diálogo que nos regresa a un recuerdo. Así, de nuevo la relativa oscuridad que nos hace volver a nuestros pasos de

${ }^{7}$ Gaudreault, André y Jost François, El relato cinematográfico. P. 90. 
derecha a izquierda con la numeración de objetos de ese espacio laberíntico en el que nos encontramos desorientados en el espacio del espectador. Los dos espacios, tanto el profílmico como el del espectador, han sido transgredidos desde el principio. El primero por la oscuridad del encuadre y el segundo por la multiplicación del espectador dentro del filme. Entre los planos secuencia ocho y nueve del primer plano de un pasillo con sus estatuas volvemos a la oscuridad y a la persistencia de la voz en la enumeración de objetos del hotel.

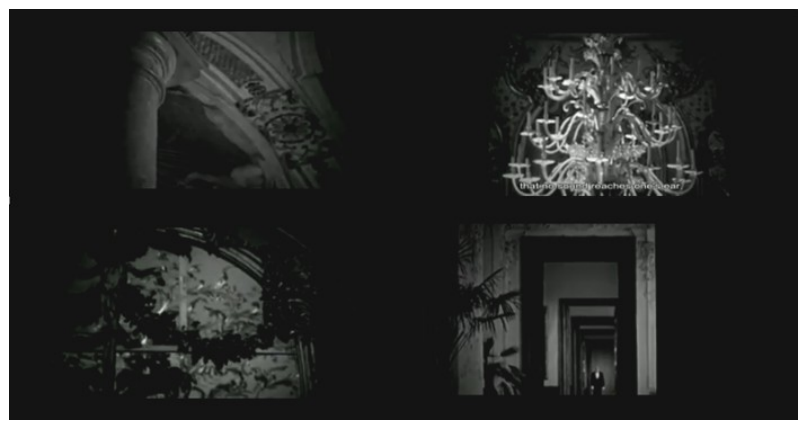

Figura 1. Primer elemento: espacios apenas iluminados con descripción de objetos y de formas. La numeración de éstos se repite a lo largo del largometraje.

En medio de la oscuridad y con la voz de guía, el «gran imaginador» muestra a los espectadores de una representación que se está llevando a cabo. Uno a otro observamos los rostros de los espectadores que se distinguen en una tenue iluminación de tenebrismo, misma que nos hace pensar de nuevo en la arquitectura barroca a la que nos ha introducido el filme. Todos observan una puesta en escena, dentro del filme, cuyo fondo nos devuelve al escenario de la pintura de un jardín francés. Frente a la pintura del escenario 
un actor y una actriz dialogan, la tensión se presenta. Él quiere que huyan juntos. Los espectadores del teatro dentro del filme los observan con su vestimenta opulenta y completamente hieráticos, como si fueran estatuas griegas captadas en una mirada petrificada por la eternidad. De nuevo la cámara presta para una nueva transgresión fragmentará los rostros de los espectadores pues la secuencia comenzará a cortar la totalidad de los rostros. El cierre de la obra de teatro se interrumpe con el primer sonido diegético aparte de la voz: una campana suena. La actriz dice: «voilà, maintenent, je suis a vous» ${ }^{8}$ y el telón cae. Tanto la pintura del jardín en el pasillo como el mismo jardín como fondo del escenario nos muestran continuidad de la misma situación en momentos distintos, una semiótica de la semejanza dirige la conformación de la mirada: un jardín en la pintura es, en apariencia, el mismo en la escenografía de una obra de teatro que, de nuevo, en apariencia, es el mismo en el que se da el encuentro entre un hombre y una mujer en el filme. Esa misma sensación de continuidad, fundada a través de la imagen, la volvemos a vivir a través de una enumeración de objetos en una voz extranjera, en la voz de un personaje de teatro, en la voz de un hombre que habla con una mujer, pero en esta ocasión el elemento de la repetición es sonoro. Así, la repetición siempre muestra una diferencia, aunque se «presente» en la misma forma. La fotografía, en cambio, de Faustine aparecerá por vez primera cuando el hombre «extranjero» busca convencerla de que se conocieron el año pasado en Marienbad, y ella aún con el testimonio de la imagen fotográfica se rehúsa a creerlo. Esa resistencia será la del olvido. La fotografía, y su condición

\footnotetext{
${ }^{8}$ "Así que, ahora, soy suya». Esta referencia de la actriz de la puesta en escena representando a Faustine dentro del filme evoca justamente a Fausto, recordemos que en la versión alemana de Goethe son las campanadas las que anuncian la irremediable paga del Dr. Fausto para Mefistófeles.
} 
ontológica, a lo largo del filme será testimonio del encuentro, la mujer sonriendo en el jardín vestida de blanco, se presenta como la prueba irrefutable no sólo de que se conocen sino que esa escena ha sido repetida una y otra vez. La fotografía además, como lo plantea Benjamin, es un disparo que fija un momento para siempre, en la película la fotografía es testigo y testimonio de la acción que ahí ocurre.

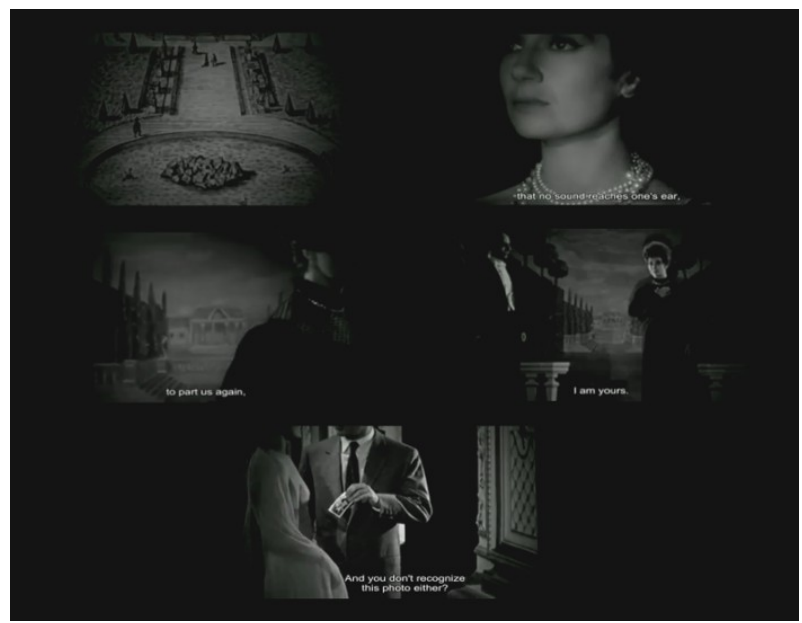

Figura 2. Segundo elemento: las artes. En primer lugar, aparece la pintura del jardín en los planos secuencia de inicio, después los espectadores del teatro, en tercer lugar de nuevo el jardín como escenografía del teatro y en último lugar la fotografía como testimonio de su encuentro un año atrás en Marienbad. Todos estos elementos también se repetirán a lo largo del filme.

Como en un círculo, la voz que repite cuáles son los espacios dentro del filme: columnas, salones vacíos, suelo, lámpara, formas barrocas, etcétera. Pero ahora esa numeración tiene otra función que nos dirige al elemento de yuxtaposición número tres: el olvido y la memoria. Ya sea el hombre dentro de la obra de teatro, dentro del filme, que 
intenta convencer a la mujer (Faustine) que huya con él; o también el hombre en el filme que intenta convencer a una segunda mujer (Faustine, también) que huya con él y que se conocieron el año pasado ahí mismo, en Marienbrad. Los dos hombres cine-teatro, retoman la numeración de objetos y descripción de espacios, para estimular la memoria de la mujer que al parecer a olvidado la promesa y el encuentro llevado a cabo para convencerla que el acuerdo de fuga se había pactado ya, tal pareciera que la repetición de dichos objetos sirviera para entrar en una especie de trance hipnótico para conseguir dar con el recuerdo. Y, entonces, huir. Él convoca a la memoria, ella al olvido. Pero ningún personaje, ningún objeto, ningún detalle del filme puede huir de la repetición que está siendo llevada a cabo conforme la imagen, automática, se mueve en una inercia de un presente tenaz y persistente. Hay tres recuerdos que él insiste en convocar: un encuentro en la recámara de la mujer, el segundo encuentro en la terraza con el jardín de fondo y el tercero la fotografía que ya habíamos aludido en el elemento de las artes. Es en este tercer elemento en donde el hombre confiesa su necesidad de fuga: el año pasado en Marienbad le disparan a quemarropa a la mujer en su habitación. Pero jestá viva! por eso es preciso salir, no sabe para qué ni para dónde, con horror de que la escena pueda repetirse. La mujer se resiste a creerlo, lo rechaza. En su habitación, sola, buscando una respuesta en uno de sus cajones encuentra no sólo con una fotografía, sino con la misma imagen fotográfica que se repite innumerables veces hasta el borde. Con las fotografías colocadas en el sillón Luis XV la mujer comprende que quien penetra en su habitación en ese instante viene a asesinarla. Los elementos de repetición del mismo filme nos van mostrando el rostro del horror: la escena de un crimen. 


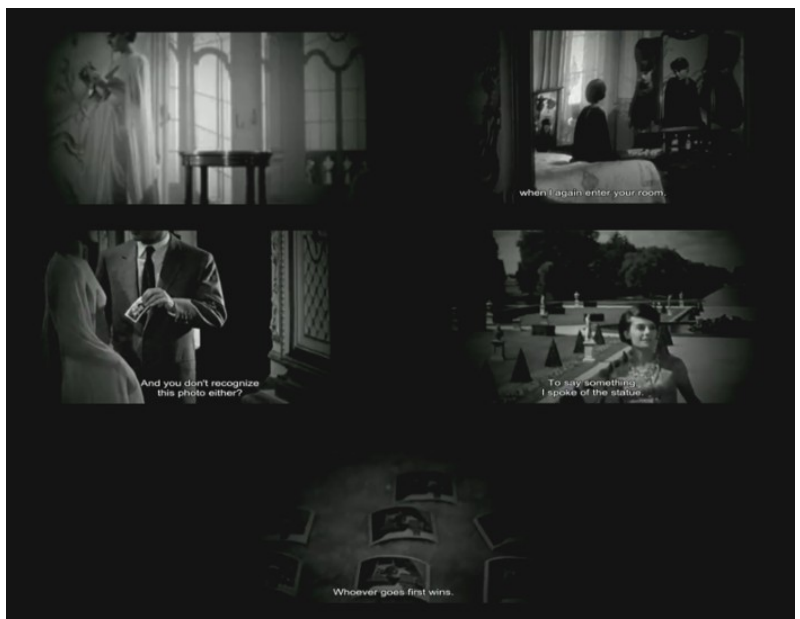

Figura 3. Tercer elemento: memoria y olvido. El extranjero (el fugitivo) intenta convencer a la mujer de cómo se conocieron el año pasado en Marienbad. Los recuerdos a los que hace alusión siempre son diferentes, se repiten aleatoriamente. La fotografía sin embargo es la misma y descubre un cajón llena de las mismas instantáneas justo antes de que su asesino entre. Vuelve a olvidar.

La multiplicación de las fotografías y la disparidad en los recuerdos del encuentro entre el hombre y la mujer nos llevan al cuarto elemento de yuxtaposición y repetición: El juego. En el hotel, entre las caminatas pasando por los mismos pasillos infinitos del hotel barroco, con la misma iluminación, pero con diferencias sutiles nos encontramos con los salones de juego. Tal como los recuerdos en el pozo de la memoria de la mujer se van intercambiando para salir emergentes, así los juegos de azar se intercambian en la película. Por eso volvemos al mismo lugar una y otra vez, pero por distintos caminos. Para poder comprender qué es lo que está pasando dentro del relato entramos en una especie de delirio en el que los recuerdos, la fotografía, los 
diálogos y los escenarios se mueven como fichas de dominó produciendo una sensación de desorientación en medio de la repetición de la trama.

El montaje es en el pensamiento «el proceso intelectual» mismo o aquello que, bajo el choque, piensa el choque. Ya la imagen, visual o sonora, tiene armónicas que acompañan a la dominante sensible y entran por su cuenta en relaciones suprasensoriales: es eso, la onda de choque o la vibración nerviosa, tal que ya no podemos decir «yo veo, yo oigo», sino YO SIENTO, «sensación totalmente fisiológica»?

En ese choque al que alude Deleuze, en las posibilidades no de las piezas colocadas en la mesa de juego que es el filme, sino en su relación heterogénea es en donde se inserta esa sensación fisiológica de desorientación propuesta por Resnais, porque efectivamente los elementos son los mismos, pero no así la forma en la que se relacionan a lo largo del filme. El montaje propuesto es la desarticulación de una coherencia temporal por una coherencia de signos que se repiten para cambiar constantemente la noción de orientación dentro del relato. En los elementos del juego está implícita la noción de azar, en el caso de la película se hace referencia a tres juegos: al dominó, a las cartas y al nim. En el caso del último juego, el Nim, la importancia de la rivalidad es crucial pues son dos jugadores que a través de una serie de movimientos deberán jugar hasta que la última ficha sea la que decida al ganador.

\footnotetext{
${ }^{9}$ Deleuze, Gilles. Imagen tiempo. Estudios sobre cine II. P. 212.
} 


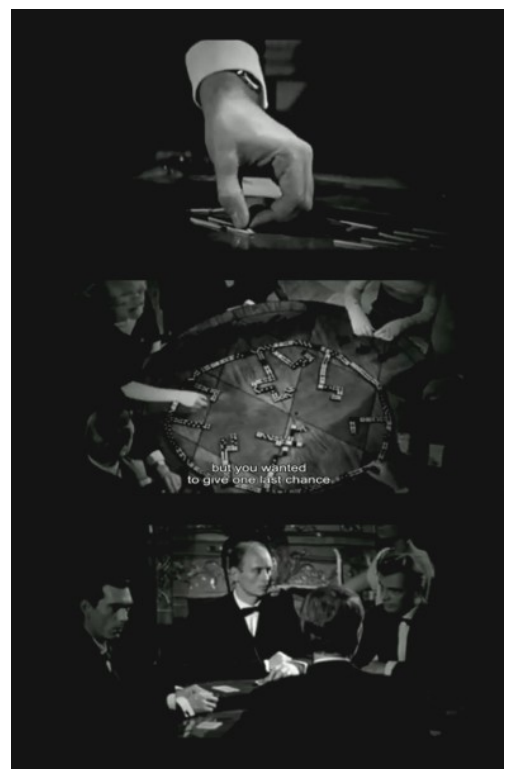

Figura 4. Cuarto elemento: los juegos de azar. Los que podemos observar a lo largo del cortometraje serán: la cartas, el dominó y el Nim.

Los elementos referidos para el análisis de L'année dernière a Marienbad apuntan hacia un cine que reflexiona sobre el propio cine. En la forma en la que constantemente nos sumerge en las tinieblas tratando de escapar del espacio como alguien que quiere ensayar saltar fuera de su propia sombra. Con su relación con las artes, en la presentación de la fotografía como testigo de algo que, no obstante, se ha querido olvidar pero se encuentra como testigo irrefutable de su condición ontológica. Con la pintura como aquella cualidad de la imagen que realiza una estética de la aparición, que no está en el mundo y que sin embargo crea su propia realidad. Con la representación teatral dentro de la presentación fílmica de la imagen en movimiento. Con la ilusión del cine como movimiento natural y como presentación de la desilusión al trasgredir la experiencia que nace 
desde ella misma. Todo esto, no sólo nos hace pensar que esta obra de Resnais nos está proponiendo no una relación entre cine y realidad sino que está planteando algo más profundo y complejo: que la fuente de esa misma relación está sostenida en el azar. Es decir que no hay naturaleza, sino que lo real es el azar. Aquí recordamos a Clemènt Rosset en La lógica de lo peor:

Por tanto crear significa, en definitiva, que perdonamos a los placeres de la vida el que no sean necesarios; que consentimos añadirles una doblez estética, amar por azar. Este es el principio fundamental que ni Freud ni Valéry desarrollan explícitamente, pero que se desprende del con-junto de sus dos estudios y que ilustran tanto el propio ejemplo de Valéry como el de Leonardo de Vinci: negarse a crear por azar es negarse a crear. Y probablemente también sea resultar incapaz de ello ${ }^{10}$.

El argumento mismo del filme, «Un hombre intenta convencer a una mujer de que se conocieron el año pasado en Marienbad» implica también pensar en la temporalidad de la propia imagen cinematográfica: «Revela una acción ya ocurrida y que, por lo tanto presenta ahora al espectador lo que ya ha pasado antes»", pero ese presentar al espectador lo ya ocurrido implica también un «estar ahí en vivo». Esa cápsula de imagen tiempo e imagen movimiento nos incluye en su excepción sensorial, de nuevo aparece el milagro de la discontinuidad. Al principio del ensayo se señaló al filme como un objeto mental, en este sentido de la mano de Gautreault y Jost seguimos la propuesta de las imágenes mentales: imaginaciones, alucinaciones, recuerdos. La repetición, de las imágenes mentales, nos llevan a la paradoja del personaje-narrador: desde la focalización es «el gran imaginador»

\footnotetext{
${ }^{10}$ Rosset, Clèment, La lógica de lo peor. Elementos para una filosofía trágica. Ed. Cuenco de Plata, Buenos Aires, 2013, P.240.

${ }^{11}$ Gautreault y Jost, Op. Cit.
} 
a través de quien se reproduce la experiencia, por lo que los recuerdos, la imaginación y la construcción de este nomadismo fílmico responden no a un quién, no a un personaje, sino a un nomadismo a través de la semejanza de la imagen. Cuando Alain Resnais plantea que el espectador tiene su estima, quizá se refiere a la construcción que a partir de una serie de elementos nos ofrece, para que cada uno pueda crear su propia explicación. No hay mayor estima del cine que la del pensamiento del otro, la distancia del otro, la duda que establece, del juego al que invita. Sin duda muchos elementos que no alcanzamos a imaginar nos faltan de pronunciar en este breve ensayo, pero relacionarse con filme a partir de él mismo y los elementos que nos proporcionan los teóricos del cine nos ha planteado ya un punto de inicio, una puerta de abre. Y permanece ese bloque de sensaciones en el que hay existencia, vida encerrada en el laberinto del filme y que está condenada a repetir su propio reconocimiento, y mejor aún: un exterior, una interpretación propia en este bello universo surgido del azar.

\section{REFERENCIAS}

Bioy Casares, Adolfo La invención de Morel. Ed. Cátedra, Madrid, 2015.

Badiou, Alain, Pensar el cine 1, imagen, ética y filosofía. Ed.

Manantial, Buenos Aires, 2004.

Deleuze, Gilles. Bergson y las Imágenes, serie clases. Ed. Cactus,

Buenos Aires, 2017.

Deleuze, Gilles. La imagen-tiempo. Estudios sobre cine 2. Ed. Paidòs,

Barcelona-Buenos Aires-México, 1987.

Gaudreault, André y Jost François, El relato cinematográfico. Ed.

Paidòs, Barcelona-Buenos Aires, 2001.

Rosset, Clèment, La lógica de lo peor. Elementos para una filosofía

trágica. Ed. Cuenco de Plata, Buenos Aires, 2013.

$$
\text { C A L E I D O }
$$




\section{ACERCA DE LA AUTORA}

Raquel Mercado Salas (reichaletheia@hotmail.com) es licenciada en filosofía por la UAA, Maestra en Filosofía e Historia de las Ideas por la Universidad de Zacatecas y Doctorante en Filosofía, en el área de Estética y Filosofía del Arte en la Universidad de Guanajuato. Actualmente está desarrollando una investigación doctoral sobre el problema de la ironía y las discusiones enmarcadas entre arte y filosofía. Miembro funda-dor de la AZECME (Asociación zacatecana de estudios clásicos y medievales) y la AEEFA (Asociación de estudios éticos y filosóficos de Aguascalientes). Profesora de Tiempo completo del Centro de las Artes y la Cultura de la UAA, con áreas de especialización en Iconología e Iconografía, Arte Clásico y Arte Contemporáneo (ORCID 0000-0003-20372613).

Recibido: 09/01/2019

Aceptado: 21/04/2019

CÓMO CITAR ESTE ARTÍCULO

Mercado Salas, R. (2020). L’année dernière a Marienbad, de Alain Resnais. Caleidoscopio - Revista Semestral de Ciencias Sociales y Humanidades, 23(42), 211-226. doi:10.33064/42crscsh2159 